\title{
Current insights of inspiratory muscle training on the cardiovascular system: a systematic review with meta-analysis
}

This article was published in the following Dove Press journal: Integrated Blood Pressure Control

\author{
Graziella FB Cipriano ${ }^{1,2}$ \\ Gerson Cipriano Jr ${ }^{1,2}$ \\ Francisco V Santos ${ }^{1,3}$ \\ Adriana M Güntzel Chiappa ${ }^{4}$ \\ Luigi Pires ${ }^{5}$ \\ Lawrence Patrick Cahalin ${ }^{2}$ \\ Gaspar R Chiappa ${ }^{5,6}$ \\ 'Physical Therapy Department, \\ University of Brasilia, Brasilia, Brazil; \\ ${ }^{2}$ Department of Physical Therapy, \\ University of Miami Miller School Of \\ Medicine, Coral Gables, FL, USA; \\ ${ }^{3}$ Department of Education and Training in \\ Oncology, Cancer Institute of São Paulo, \\ São Paulo, Brazil; ${ }^{4}$ Intensive Care Unit, \\ Hospital de Clinicas de Porto Alegre, \\ Porto Alegre, Brazil; ${ }^{5}$ Centro \\ Universitário do Planalto Central \\ Professor Apparecido dos Santos, \\ Brasilia, Brazil; ' University Center, \\ UniEvangelica, Anapolis, Goias, Brazil
}

Correspondence: Gaspar R Chiappa Physical Therapy Department, Centro Universitário do Planalto Central

Professor Apparecido dos Santos, Setor Leste no. 02, Área Especial - Gama - DF CEP, Brasília, DF 724445-020, Brazil Tel +556130353900

Email gaspar.chiappa@gmail.com
Background: Cardiorespiratory limitation is a common hallmark of cardiovascular disease which is a key component of pharmacological and exercise treatments. More recently, inspiratory muscle training (IMT) is becoming an effective complementary treatment with positive effects on muscle strength and exercise capacity. We assessed the effectiveness of IMT on the cardiovascular system through autonomic function modulation via heart rate variability and arterial blood pressure.

Methods: Randomized controlled trials (RCTs) were identified from searches of The Cochrane Library, MEDLINE and EMBASE to November 2018. Citations, conference proceedings and previous reviews were included without population restriction, comparing IMT intervention to no treatment, placebo or active control.

Results: We identified 10 RCTs involving 267 subjects (mean age range 51-71 years). IMT programs targeted maximum inspiratory pressure (MIP) and cardiovascular outcomes, using low $(n=6)$ and moderate to high intensity $(n=4)$ protocols, but the protocols varied considerably (duration: 1-12 weeks, frequency: 3-14 times/week, time: 10-30 mins). An overall increase of the MIP $\left(\mathrm{cmH}_{2} \mathrm{O}\right)$ was observed $\left(-27.5795 \%\right.$ CI $\left.-18.48,-37.45, I^{2}=64 \%\right)$, according to weighted mean difference $(95 \% \mathrm{CI})$, and was accompanied by a reduction of the low to high frequency ratio $\left(-0.7295 \% \mathrm{CI}-1.40,-0.05, I^{2}=50 \%\right)$. In a subgroup analysis, low- and moderate-intensity IMT treatment was associated with a reduction of the heart rate (HR) $\left(-7.5995 \% \mathrm{CI}-13.96,-1.22 \mathrm{bpm}, I^{2}=0 \%\right)$ and diastolic blood pressure (DBP) $(-8.29$ $\left.[-11.64,-4.94 \mathrm{mmHg}], I^{2}=0 \%\right)$, respectively.

Conclusion: IMT is an effective treatment for inspiratory muscle weakness in several populations and could be considered as a complementary treatment to improve the cardiovascular system, mainly HR and DBP. Further research is required to better understand the above findings.

Keywords: breathing exercises, respiratory muscle training, cardiovascular system

\section{Introduction}

Inspiratory muscle weakness may induce several impairments in both healthy ${ }^{1,2}$ and athletic individuals. ${ }^{3,4}$ Similarly, studies have demonstrated that inspiratory muscle strength also has an important role in the pathophysiology of exercise limitation in several clinical conditions. ${ }^{5}$ More recently, studies have found that maximal inspiratory pressure (MIP) is strongly correlated with $\mathrm{VO}_{2}$ peak in patients after acute myocardial infarction and heart failure, ${ }^{6}$ reinforcing the influence of the inspiratory muscles on functional capacity. 
Furthermore, studies suggest that inspiratory muscle strength may influence central hemodynamic measurements at rest, including cardiac output, mean arterial pressure and vascular resistance in heart failure patients. ${ }^{7}$ In this sense, inspiratory muscle training (IMT) has been tested to evaluate its effect over the autonomic nervous activity and blood pressure control. ${ }^{8-10}$ Ferreira et $\mathrm{al}^{9}$ demonstrated a significant influence of IMT on 24-hrs ambulatory blood pressure monitoringby reducing systolic and diastolic blood pressure (SDP and DBP) 7.9 and 5.5 $\mathrm{mmHg}$, respectively.

More recently, IMT has been evaluated as an adjunct therapy to improve autonomic modulation due to the recognized respiratory effects. According to several studies, IMT may reduce sympathetic activity ${ }^{9,11}$ through respiratory muscle metaboreflex attenuation, ${ }^{12}$ improving functional capacity and physical performance. ${ }^{12-15}$ Therefore, the purpose of this study was to systematically review the effects of the IMT on global cardiovascular function through autonomic function modulation of heart rate variability (HRV) and arterial blood pressure.

\section{Methods}

This systematic review with meta-analysis was conducted following the PRISMA Statement for Reporting Systematic Review Analysis. ${ }^{16}$

\section{Criteria for considering studies for this review}

\section{Type of studies}

Controlled clinical trial studies evaluating IMT effects on cardiovascular function were included in the systematic review.

\section{Types of participants}

The trials evaluating IMT effects on blood pressure and autonomic modulation, without population restriction. The eligibility criteria to select studies were: i) the primary objective was related to the effects of IMT on the cardiovascular autonomic nervous system, arterial blood pressure and heart rate (HR), and ii) randomized clinical trials. Exclusion criteria were non-randomized trials and articles addressing other breathing exercises modalities (yoga, slow and fast breathing, expiratory muscle training).

\section{Types of intervention}

We included studies examining a program of IMT ( $\geq 1$ week treatment) offered as a sole intervention or as an adjuvant to another form of exercise. Interventions could be compared to either an inactive control (eg, no treatment, placebo, or sham NMES) or an active control such as an alternative form of exercise. A placebo intervention was defined as a treatment group in which an identical IMT, but without resistance or with minimum resistance. A control intervention was defined as either no treatment (non-active) or another treatment modality (active control) not including IMT protocol.

\section{Types of outcome}

The primary outcomes were HR (measured by beats per minute, bpm), SBP, DBP and mean blood pressure (measured by millimeters of mercury, $\mathrm{mmHg}$ ) and HRV frequency domain components (LF, HF, and LF/HF; measured in normalized units). Inspiratory muscle strength (MIP; measured by $\mathrm{cmH}_{2} \mathrm{O}$ ).

\section{Search method for identification of studies}

The Cochrane Library (online version 2018), PUBMED (1962-2018), EMBASE (1980-2018) electronic databases were searched to identify eligible studies. Two reviewers analyzed the results independently (GRC and GCJ). Searches were limited to randomized, controlled trials (RCTs) and a filter was applied to limit the search to human trials. No language restrictions were included. A sensitive search strategy for identifying RCTs was employed [16]. Additional studies were identified from the reference lists of the retrieved studies.

\section{Keywords employed during searches}

("Breathing Exercises"[Mesh] OR "Maximal Respiratory Pressures"[Mesh] OR "Respiratory Muscles"[Mesh] OR "Muscle Strength"[Mesh]) AND ("Blood Pressure"[Mesh] OR “Arterial Pressure"[Mesh] OR "Baroreflex”[Mesh] OR "Heart Rate"[Mesh] OR "Blood Pressure Monitoring, Ambulatory" OR "Autonomic Nervous System"[Mesh] OR "Vascular Resistance"[Mesh] OR "Sympathetic Nervous System"[Mesh]) AND ((Clinical Study[ptyp] OR Clinical Trial[ptyp] OR Clinical Trial, Phase I[ptyp] OR Clinical Trial, Phase II[ptyp] OR Clinical Trial, Phase III[ptyp] OR Clinical Trial, Phase IV[ptyp] OR Controlled Clinical Trial [ptyp] OR Pragmatic Clinical Trial[ptyp] OR Randomized Controlled Trial[ptyp] OR Research Support, American Recovery and Reinvestment Act[ptyp] OR Research Support, N I H, Extramural[ptyp] OR Research Support, N I H, Intramural[ptyp] OR Research Support, Non U S Gov't [ptyp] OR Research Support, U S Gov't, Non P H S[ptyp] OR Research Support, U S Gov't, P H S[ptyp] OR Research Support, US Government[ptyp]) AND Humans[Mesh] 


\section{Data collection and analysis}

Study selection

The articles retrieved during the searches were initially screened based on the title and abstract for the exclusion of clearly irrelevant studies. For selection, abstracts had to identify the study design, appropriate population and relevant components of the intervention, as described above. Full-text articles of all potentially relevant RCTs were obtained and assessed independently by two reviewers (GRC and GCJ) for eligibility based on the defined inclusion criteria.

\section{Quality assessment}

The risk of bias in the eligible RCTs was assessed by a single reviewer (FVSC) and verified by a second reviewer (GRC). The following aspects of methodological quality were assessed: concealment of the allocation, intention-totreat analysis, outcome assessment blinding and description of losses and exclusions. Quality was also evaluated globally using the scale proposed by PEDro scale. ${ }^{17}$

\section{Data extraction}

Relevant data regarding inclusion criteria (study design, participants, duration, frequency, intensity, comparisons, and outcomes), the risk of bias (randomization, blinding, attrition, and control) and results were extracted. If the study had more than two groups, we included those that presented with the greater effect size. Data extraction was performed by a single reviewer (GRC) and checked by a second reviewer (GCJ). Disagreements were resolved by consensus. The agreement ratio before amending any discrepancies was assessed using the Kappa coefficient, which was higher than 0.90. Authors were contacted when necessary for clarifications or to obtain further outcome details.

\section{Statistical analysis}

The data were processed following the Cochrane Handbook for Systematic Reviews of Interventions. For continuous variables, net changes were compared (ie, IMT group vs control group) by the weighted mean difference (WMD) and $95 \% \mathrm{CI}$. The SD was calculated for each study based on the change score method. Heterogeneity among the studies was explored qualitatively by comparing the characteristics of the studies and quantitatively using the chi-squared test of heterogeneity and the $I^{2}$ statistic. When appropriate, the results of the studies were combined for each outcome to determine the overall estimate of the treatment effect. The effect model for meta-analysis was elected based on qualitative and quantitative analyses as well as the analysis of publication bias. All analyses were conducted using Review Manager version 5.3.

\section{Results}

\section{Identification and selection of studies}

The initial search led to the identification of 975 studies, among which 855 were considered potentially relevant based on the title and abstract. Twenty-nine potentially relevant studies were retrieved for detailed analysis. ${ }^{8,11,18-34}$ Only 10 articles met the eligibility criteria. ${ }^{9,35-43}$ Figure 1 shows the flowchart of the study selection process. Excluded studies and the reasons for their exclusion are detailed in Table 1.

\section{Description of studies and participants}

The 10 studies analyzed involved a total of 267 subjects. Descriptions of all studies are presented in Table 2.

\section{Interventions characteristics}

The most common IMT intensity was low-intensity. Six studies compared the effects of low-intensity IMT, $, 35,36,38,40,43$ two studies examined moderate intensity

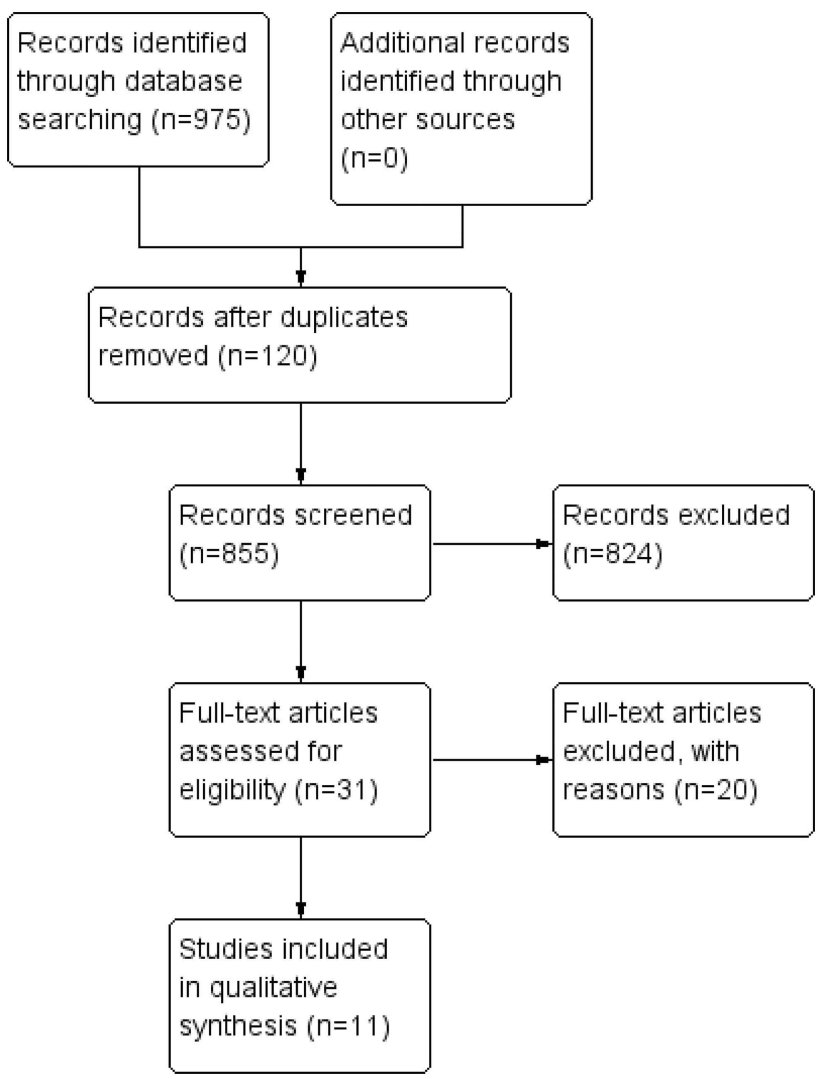

Figure I Study flow diagram. 
Table I Characteristics of the excluded studies

\begin{tabular}{|c|c|}
\hline Study & Reason for exclusion \\
\hline Souza et al ${ }^{18}$ & Non-randomized trial and \\
\hline Jones et $\mathrm{al}^{19}$ & Other breathing exercise \\
\hline Posser et $\mathrm{al}^{8}$ & Protocol study \\
\hline Drozdz et $\mathrm{al}^{20}$ & Other breathing exercise \\
\hline Gething et $\mathrm{al}^{21}$ & Comparison between intensities different \\
\hline Jaenisch et $\mathrm{al}^{30}$ & Animal study \\
\hline Laohachai et $\mathrm{al}^{23}$ & $\begin{array}{l}\text { Non-randomized study and without control } \\
\text { group }\end{array}$ \\
\hline Kaminski et al ${ }^{11}$ & Absence of baseline and post-intervention data \\
\hline Laoutaris et $\mathrm{al}^{24}$ & $\begin{array}{l}\text { Non-randomized study and without control } \\
\text { group }\end{array}$ \\
\hline Logtenberg et $\mathrm{a}^{25}$ & Other breathing exercise \\
\hline Mourya et $\mathrm{al}^{26}$ & Other breathing exercise \\
\hline Tong et $\mathrm{al}^{27}$ & $\begin{array}{l}\text { Inspiratory muscle training plus functional } \\
\text { exercise }\end{array}$ \\
\hline Passfield et $\mathrm{al}^{28}$ & $\begin{array}{l}\text { Hyperpnea during respiratory muscle training } \\
\text { and without outcomes }\end{array}$ \\
\hline Correa et $\mathrm{al}^{29}$ & $\begin{array}{l}\text { Heart rate, systolic and diastolic blood pressure } \\
\text { were not shown }\end{array}$ \\
\hline Jaenisch et $\mathrm{al}^{22}$ & Animal study \\
\hline Sangthong et $\mathrm{al}^{31}$ & Other breathing exercise \\
\hline Silva et $\mathrm{al}^{34}$ & Data without mean \\
\hline Vivodtzev et $\mathrm{al}^{32}$ & Mixed intervention \\
\hline Ditterline et $\mathrm{al}^{33}$ & Absence of baseline and post-intervention data \\
\hline
\end{tabular}

IMT $^{39,41}$ and two studies examined high-intensity IMT. ${ }^{37,42}$ Four studies used a medium resistance spring load device (PowerBreathe Classic, PoweBreathe International Ltd., Warwickshire, England, UK) to produce IMT, ${ }^{39-42}$ five studies used another spring-loaded device (Threshold IMT, Philips, Rotterdam, Netherlands) ${ }^{9,36,38,39,43}$ and one used another form of IMT (Threshold PEP, Philips). ${ }^{35}$ The studies were quite heterogeneous, and Table 3 provides a summary of the interventions employed in the different studies.

\section{Quality of the studies}

The methodological quality of the eligible RCTs is presented in Table 3. The quality of most studies was poor to good. According to PEDro scale, six studies reached 4 to 5 points and four studies 6 to 7 points.

\section{Effect of IMT on inspiratory muscle strength}

The most frequent training intensity used was $30 \%$ of the MIP defined as low-intensity and four studies used $50 \%$ of the MIP (moderate-high intensity). ${ }^{44}$ Treatment duration

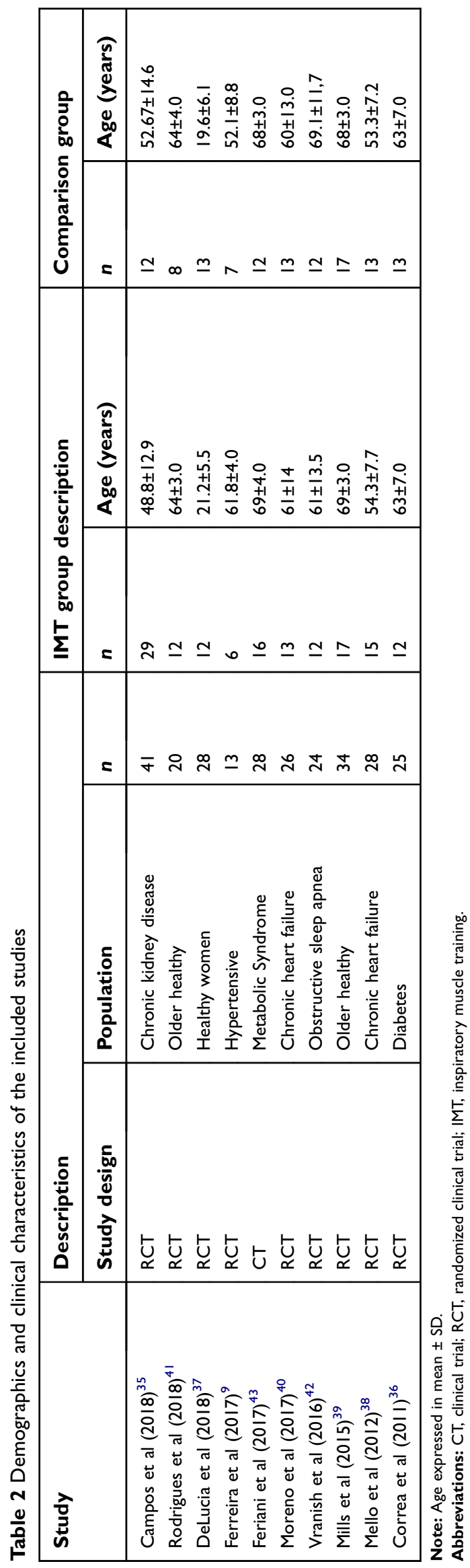


Table 3 Intervention description of the included studies

\begin{tabular}{|c|c|c|c|c|c|c|c|c|}
\hline \multirow[t]{2}{*}{ Study } & \multicolumn{6}{|c|}{ IMT group description } & \multirow{2}{*}{$\begin{array}{l}\text { Comparison } \\
\text { group } \\
\text { Description }\end{array}$} & \multirow{2}{*}{$\begin{array}{l}\text { Score } \\
\text { PEDro }\end{array}$} \\
\hline & $\begin{array}{l}\text { Intensity } \\
\text { (MIP) }\end{array}$ & $\begin{array}{l}\text { Frequency } \\
\text { (day/week) }\end{array}$ & $\begin{array}{l}\text { Duration } \\
\text { (week) }\end{array}$ & Time & $\begin{array}{l}\text { Intensity } \\
\text { type }\end{array}$ & Training type & & \\
\hline $\begin{array}{l}\text { Campos et } \\
\text { al }(20 \mid 8)^{34}\end{array}$ & $\begin{array}{l}15 \mathrm{cmH}_{2} \mathrm{O} \\
20 \mathrm{cmH}_{2} \mathrm{O}\end{array}$ & 3 & 8 & $\begin{array}{l}30 \\
\operatorname{mins}\end{array}$ & Low & $\begin{array}{l}\text { Resistor Threshold } \\
\text { PEP }\end{array}$ & Control & $6 / 10$ \\
\hline $\begin{array}{l}\text { Rodrigues } \\
\text { et al } \\
(2018)^{40}\end{array}$ & $\begin{array}{l}30 \% \text { (I week) } \\
50 \% \text { after }\end{array}$ & $\begin{array}{l}2 \times \text { day } / 5-7 \\
\text { days }\end{array}$ & 5 & $\begin{array}{l}30 \\
\text { breaths }\end{array}$ & Moderate & $\begin{array}{l}\text { Resistor } \\
\text { PowerBreathe Classic }\end{array}$ & Control & $4 / 10$ \\
\hline $\begin{array}{l}\text { DeLucia et } \\
\text { al }(2018)^{36}\end{array}$ & $75 \%$ & 5 & 6 & - & High & $\begin{array}{l}\text { Resistor Pressure } \\
\text { Transducer }\end{array}$ & $\begin{array}{l}\text { Sham }(15 \% \\
\text { Plmax })\end{array}$ & $7 / 10$ \\
\hline $\begin{array}{l}\text { Moreno et } \\
\text { al }(2017)^{39}\end{array}$ & $30 \%$ & 6 & 8 & $\begin{array}{l}30 \\
\operatorname{mins}\end{array}$ & Low & $\begin{array}{l}\text { Resistor Threshold } \\
\text { IMT and } \\
\text { Powerbreathe }\end{array}$ & Control & $5 / 10$ \\
\hline $\begin{array}{l}\text { Feriani et al } \\
(2017)^{42}\end{array}$ & $30 \%$ & 3 sets & 1 & $\begin{array}{l}15 \\
\operatorname{mins}\end{array}$ & Low & $\begin{array}{l}\text { Resistor Threshold } \\
\text { IMT }\end{array}$ & Control & $5 / 10$ \\
\hline $\begin{array}{l}\text { Vranish et al } \\
(2016)^{41}\end{array}$ & $75 \%$ & Twice/day & 6 & $\begin{array}{l}30 \\
\text { breaths }\end{array}$ & High & $\begin{array}{l}\text { Resistor } \\
\text { PowerBreathe Classic }\end{array}$ & $\begin{array}{l}\text { Sham }(15 \% \\
\text { Plmax })\end{array}$ & $5 / 10$ \\
\hline $\begin{array}{l}\text { Mills et al } \\
(2015)^{38}\end{array}$ & $50 \%$ & 7 & 8 & $\begin{array}{l}30 \\
\text { breaths }\end{array}$ & Low & $\begin{array}{l}\text { Resistor } \\
\text { PowerBreathe Classic }\end{array}$ & Control & $5 / 10$ \\
\hline $\begin{array}{l}\text { Ferreira et } \\
\text { al }(2013)^{9}\end{array}$ & $30 \%$ & 7 & 8 & $\begin{array}{l}30 \\
\operatorname{mins}\end{array}$ & Low & $\begin{array}{l}\text { Resistor Threshold } \\
\text { IMT }\end{array}$ & Control & $6 / 10$ \\
\hline $\begin{array}{l}\text { Mello et al } \\
(2012)^{37}\end{array}$ & $30 \%$ & $\begin{array}{l}3 \times \text { day during } \\
7 \text { week }\end{array}$ & 12 & $\begin{array}{l}10 \\
\operatorname{mins}\end{array}$ & Low & $\begin{array}{l}\text { Resistor Threshold } \\
\text { IMT }\end{array}$ & Control & $4 / 10$ \\
\hline $\begin{array}{l}\text { Correa et al } \\
(2011)^{35}\end{array}$ & $30 \%$ & 7 & 8 & $\begin{array}{l}30 \\
\operatorname{mins}\end{array}$ & Low & $\begin{array}{l}\text { Resistor Threshold } \\
\text { IMT }\end{array}$ & Control & $6 / 10$ \\
\hline
\end{tabular}

Abbreviations: PEP, positive expiratory pressure; IMT, inspiratory muscle training; MIP, maximal inspiratory pressure.

ranged from 1 to 12 weeks. All protocols performed weekly readjustments of MIP (Table 3 ). The number of training sessions ranged from 2 to 7 sessions per week for 15-30 mins duration. Three studies were performed twice or more per day. ${ }^{38,41,42}$ Six studies set the workload at $30 \%$ MIP with a total of 113 subjects in the IMT and 89 in the control group, and 4 studies which set the workload $\geq 50 \%$ MIP with a total of 32 subjects in the IMT and 31 in the control group. Overall, IMT was associated with a significant improvement in MIP when data of all studies were pooled (10 studies, $n=263$ subjects, $\mathrm{WMD}=27.57$ cmH2O, 95\% CI $18.48-37.45 \quad$ cmH2O, $\quad I^{2}=64 \%$ ) (Figure 2). From subgroup analysis, low-intensity and moderate-high intensity IMT protocols produced similar effects from both low and high intensity protocols (low intensity: 7 studies, $n=202$ subjects; $\mathrm{WMD}=28.42,95 \% \mathrm{CI}$ 12.37-44.46 cmH2O, $I^{2}=73 \%$; moderate-high intensity, 3 studies, $n=63$ subjects; WMD $=25.55,95 \%$ CI 19.42-31.68 cmH2O, $I^{2}=73 \%$ ).

\section{Effect of IMT on hemodynamic measures Heart rate}

Overall, IMT did not influence HR when data of all studies were pooled ( 10 studies, $n=152$ subjects, $\mathrm{WMD}=-4.32 \mathrm{bpm}$, $95 \% \mathrm{CI}-9.56$ to $0.91 \mathrm{bpm}, I^{2}=0 \%$ ) (Figure $3 \mathrm{~A}$ ). In a subgroup analysis, only low-intensity IMT studies were associated with a reduction of the resting HR (4 studies, $n=108$ subjects; WMD $=-7.59 \mathrm{bpm}, 95 \%$ CI -13.96 to -1.22 bpm, $I^{2}=0 \%$ ).

\section{Systolic blood pressure}

IMT did not modify SBP in the overall analysis (05 studies, $n=63$, WMD $=-8.13 \mathrm{mmHg}, 95 \% \mathrm{CI}-21.17$ to $4.91 \mathrm{mmHg}, I^{2}=89 \%$ ). Subgroup analysis also did not 


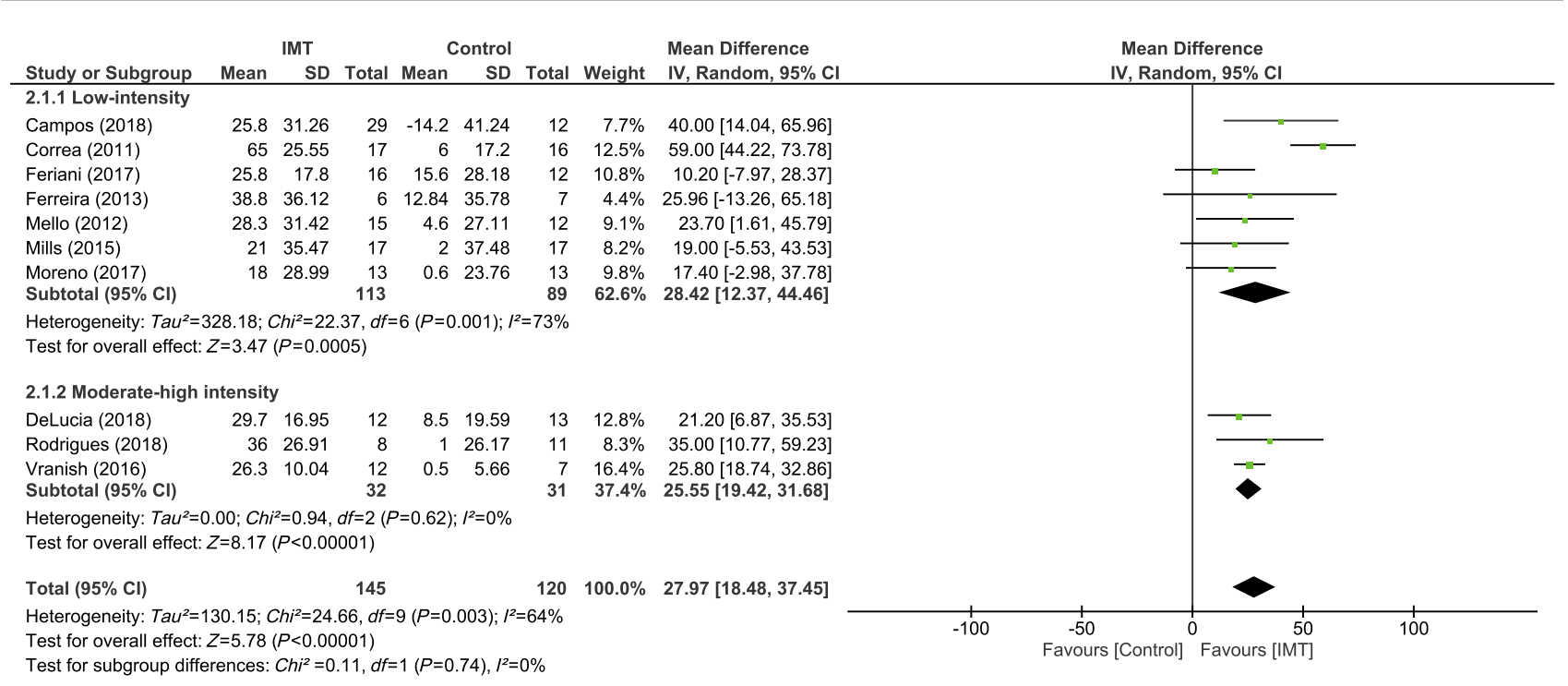

Figure 2 Forest plot depicts of inspiratory muscle training on inspiratory muscle strength compared to low and moderate-high intensity.

demonstrate effects either in low and moderate to high intensity protocols-low intensity ( 03 studies, $n=71$ subjects, $\mathrm{WMD}=-0.94 \mathrm{mmHg}, 95 \% \mathrm{CI}-10.53$ to 8.66 $\left.\mathrm{mmHg}, I^{2}=0 \%\right)$ and moderate-high intensity (02 studies, $n=44, \mathrm{WMD}=-15.79 \mathrm{mmHg}, 95 \% \mathrm{CI}-33.77$ to 2.19 $\mathrm{mmHg}, I^{2}=89 \%$ ) (Figure 3B).

\section{Diastolic blood pressure}

Overall, IMT was not associated with a significant reduction of the DBP when data of all studies were pooled (05 studies, $n=119$ subjects, WMD $=-3.30 \mathrm{mmHg}, 95 \% \mathrm{CI}$ -9.63 to $3.04 \mathrm{mmHg}, I^{2}=76 \%$ ) (Figure $3 \mathrm{C}$ ). Subgroup analysis found no positive effect of low-intensity IMT on DBP (03 studies, $n=75$ subjects; WMD $=2.12 \mathrm{mmHg}, 95 \%$ CI -1.78 to $6.01 \mathrm{mmHg}, I^{2}=0 \%$ ), but moderate-high intensity IMT was associated with a significant reduction in DBP (02 studies, $n=44$ subjects; WMD $=-8.29 \mathrm{mmHg}$, $95 \% \mathrm{CI}-11.64$ to $-4.94 \mathrm{mmHg}, I^{2}=0 \%$ ).

\section{Effect of IMT on heart rate variability measures}

\section{Low- and high-frequency component}

Overall analyses found that IMT did not favorably modulate the low- and high-frequency HRV components (Figure 4A and B). Subgroup analysis also found that low- and moderate-high intensity IMT was not associated with modulation of the low- and high-frequency HRV components.

\section{Low- to high-frequency ratio}

IMT was found to produce a slight reduction of the low- to high-frequency ratio when data of all studies were pooled
(06 studies, $n=144$ subjects, WMD $=-0.72,95 \% \mathrm{CI}-1.40$ to $-0.05, I^{2}=50 \%$ ) (Figure $4 \mathrm{C}$ ). From subgroup analysis, only one IMT study with moderate-high intensity produced a significant reduction in the low- to high-frequency ratio (01 study, $n=19$ subjects, $\mathrm{WMD}=-2.29,95 \% \mathrm{CI}$ -4.12 to $-0.46, I^{2}=$ not applicable).

\section{Discussion}

Despite the considerable heterogeneity of the IMT protocols which evaluated cardiovascular effects $\left(I^{2}>60 \%\right)$, the results reaffirmed in both general or subgroup analysis an important effect of IMT on MIP with an overall effect of $27.57 \mathrm{cmH}_{2} \mathrm{O}$ (95\% CI 18.48-37.45). Regarding the cardiovascular effect of the IMT, this review only found a small decrease in the low to high-frequency ratio following IMT treatment $-0.72(95 \%$ CI -1.40 to -0.05$)$. Moreover, from subgroup analysis, low-intensity IMT protocols were associated with an important reduction of the rest $\mathrm{HR}-7.59 \mathrm{bpm}(95 \% \mathrm{CI}-13.96$ to -1.22$)$ while moderate-high intensity protocols demonstrate a significant reduction in DBP $-8.29 \mathrm{mmHg}(95 \% \mathrm{CI}-11.64$ to -4.94 ) and greater effect on the low- to high-frequency ratio compared to the overall analysis $2.29(95 \% \mathrm{CI}-4.12$ to -0.46$)$. The effect from IMT on SBP in both overall and subgroup analysis (low and moderate-high intensity protocol) was not significant.

Selected studies on this meta-analysis included several different populations, including cardiovascular conditions (6 studies), healthy older adults (2 studies), Chronic kidney disease. (1 study), and obstructive sleep apnea (1 study). 


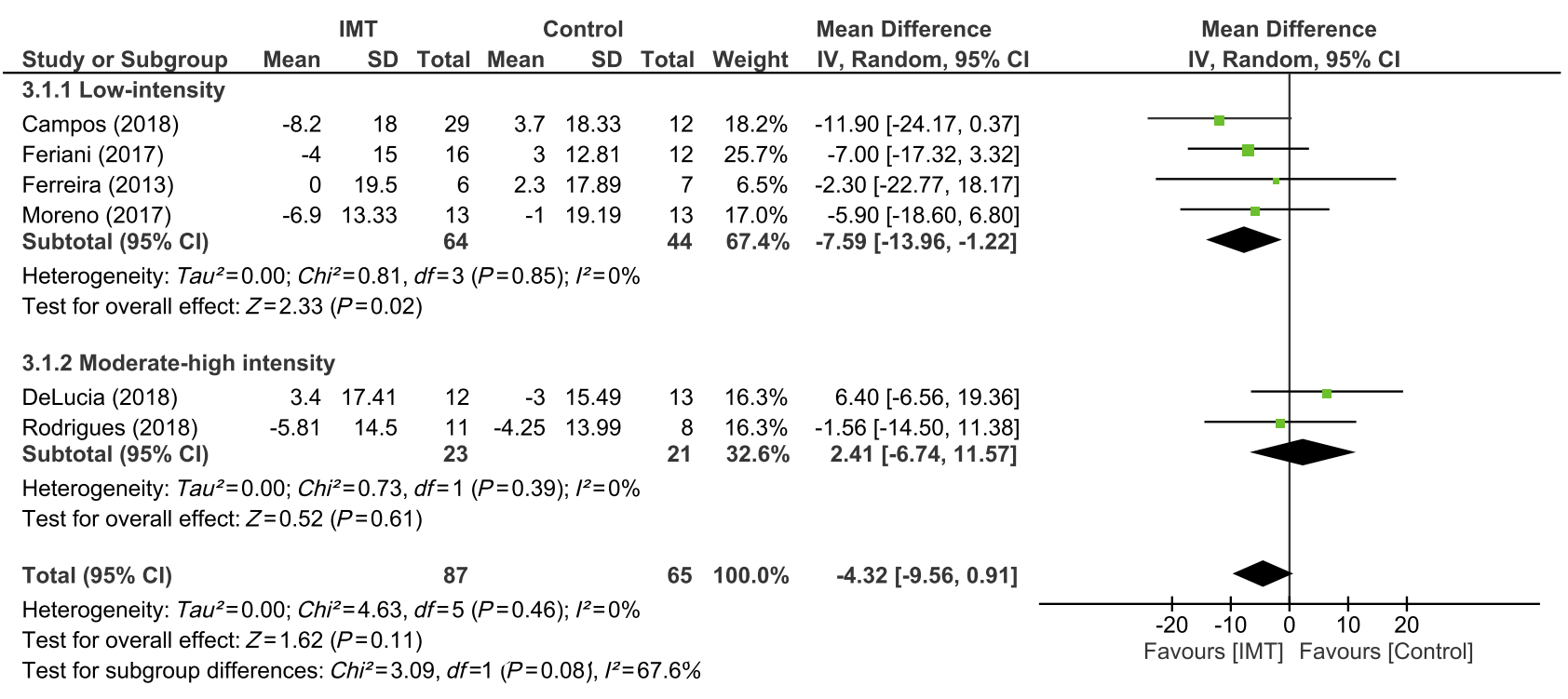

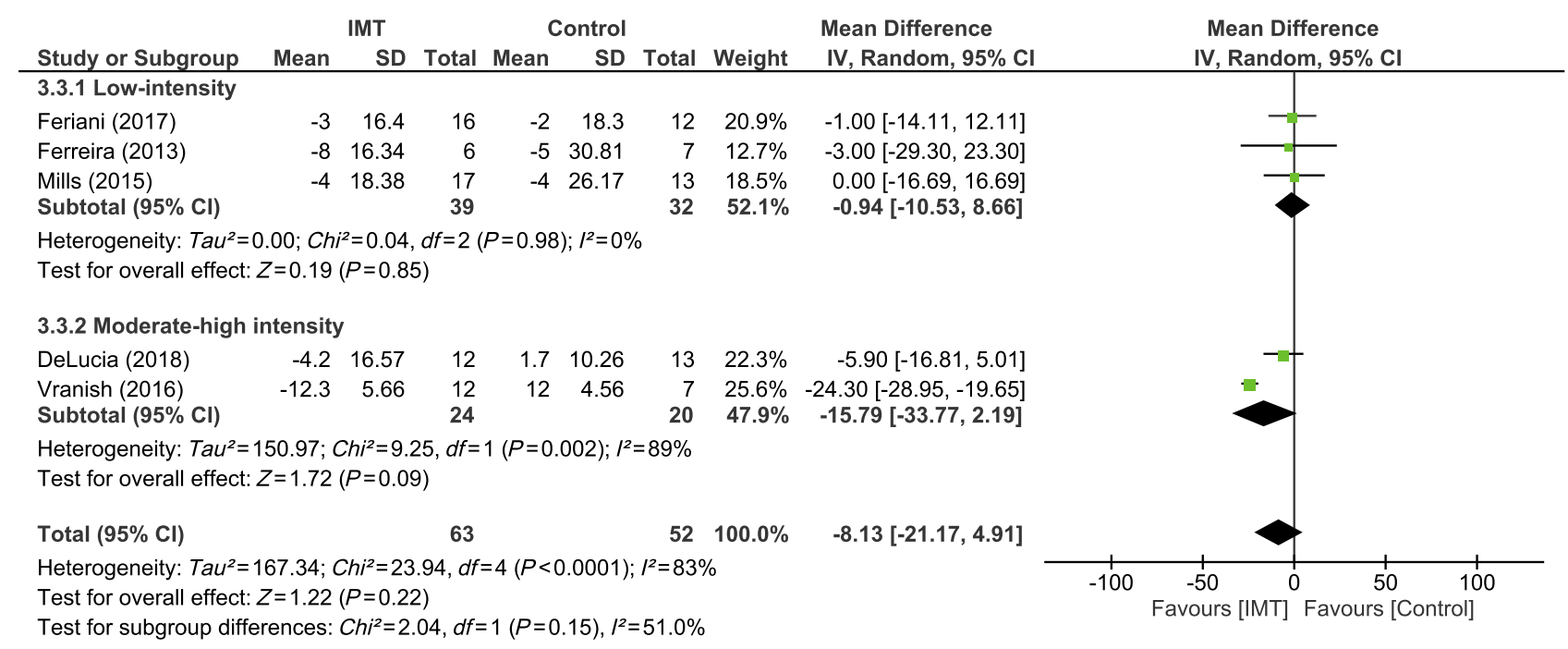

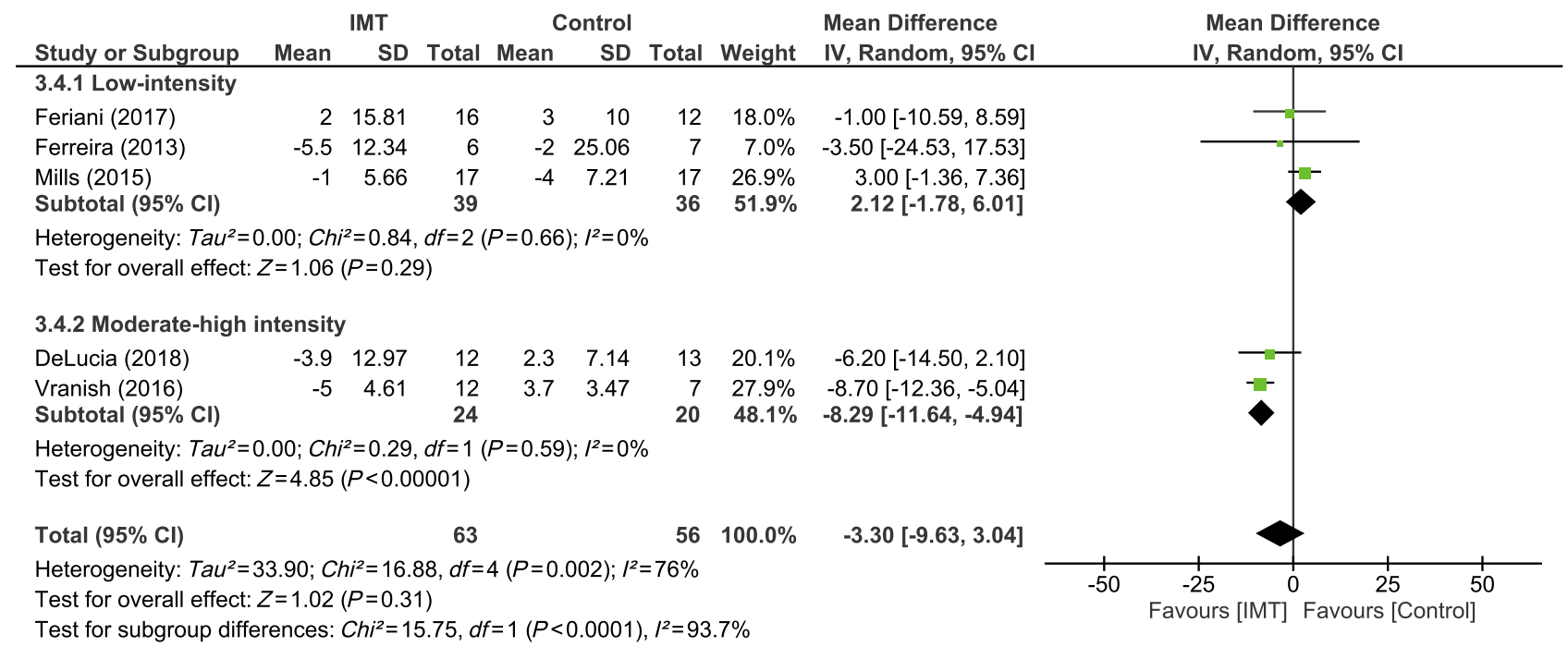

Figure 3 Forest plot depicts of inspiratory muscle training on (A) systolic blood pressure, (B) diastolic blood pressure, and (C) heart rate compared to low and moderatehigh intensity. 


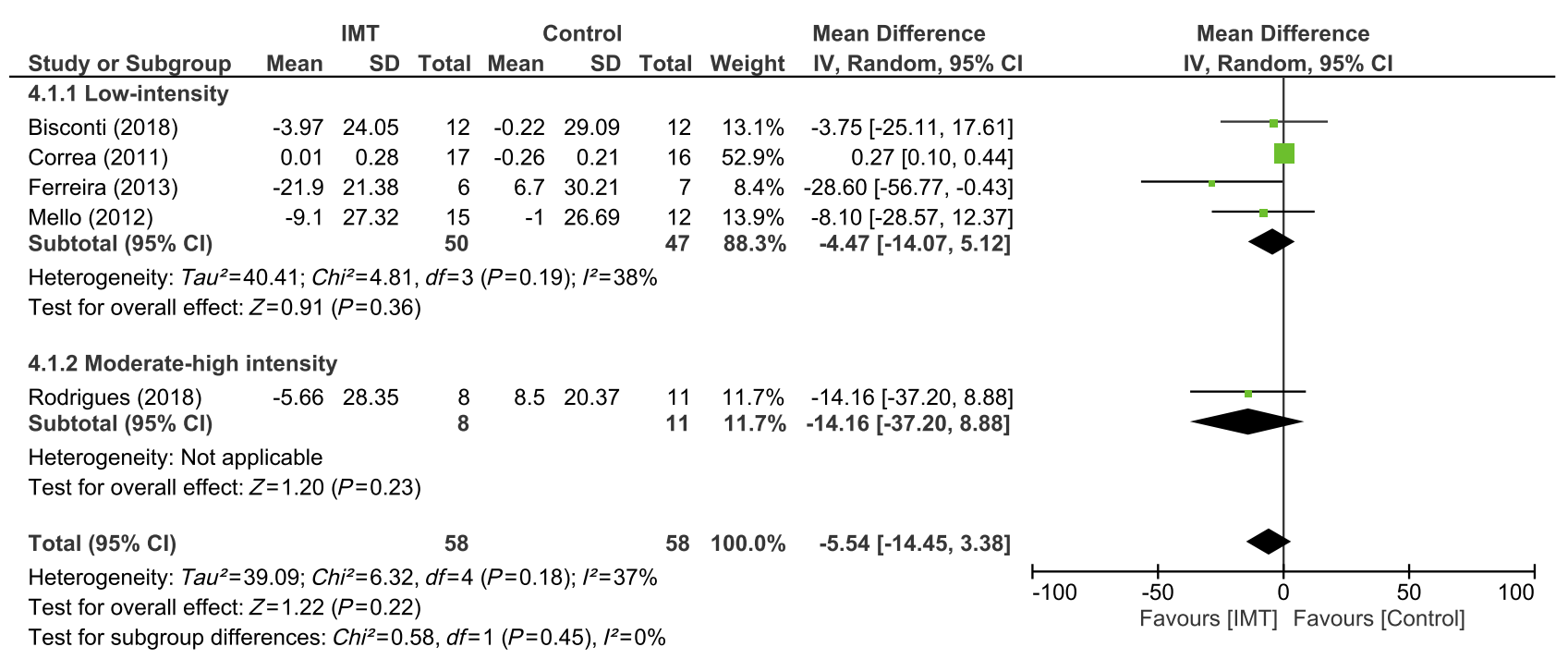

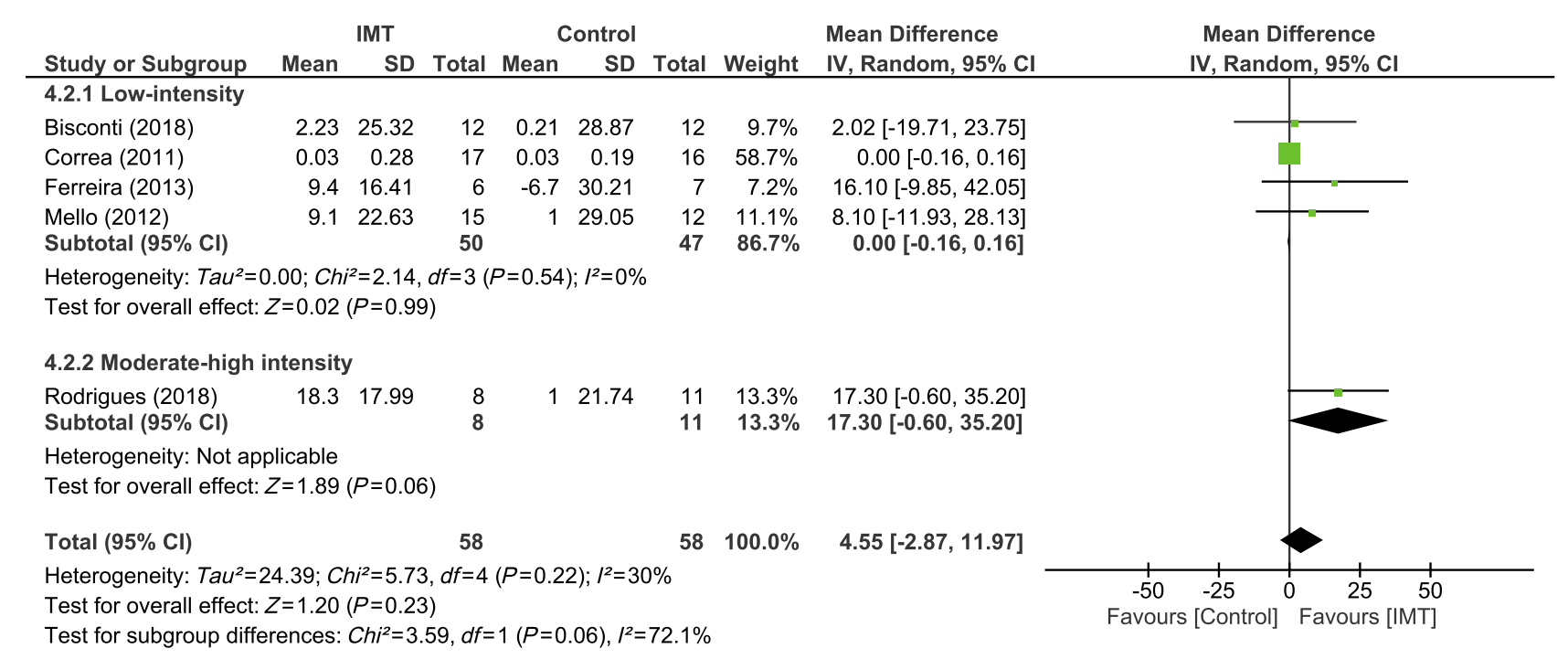

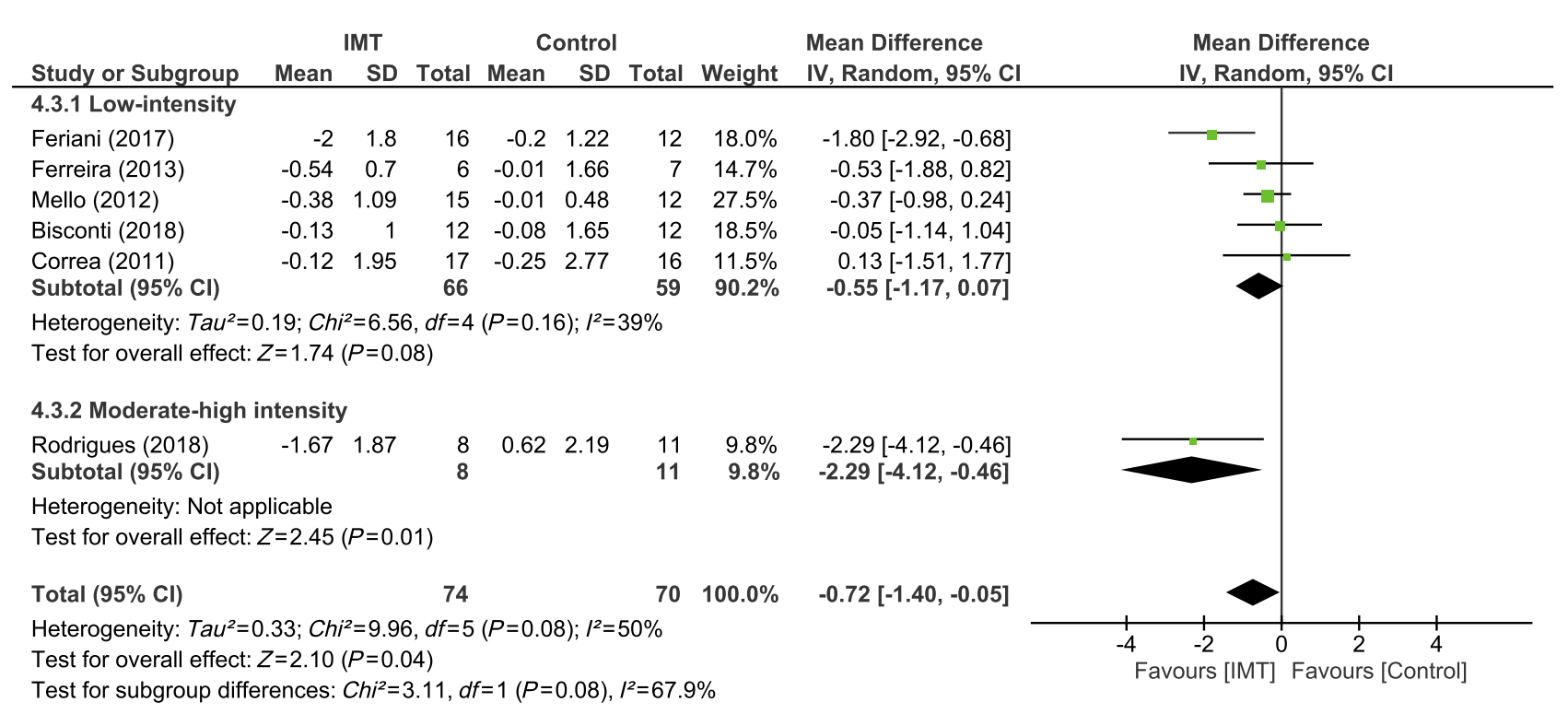

Figure 4 Forest plot depicts of inspiratory muscle training on (A) low-frequency heart rate variability, (B) high-frequency heart rate variability, and (C) low-to-high frequency ratio compared to low and moderate-high intensity. 
Therefore, the results from its meta-analysis must be evaluated with caution. Most of the above mentioned pathophysiological conditions have been strongly associated with inspiratory muscle weakness (IMW). Patients with IMW are more susceptible to muscle fatigue and consequently to metabolite accumulation which activates unmyelinated type IV phrenic afferent fibers that increases sympathetic outflow reflex activity and produces a vasoconstrictor response in resting limbs which has been referred to as "inspiratory muscle metaboreflex overactivation." 40

Cardiovascular effects of IMT have been associated with the respiratory maneuver performed during the training sessions which inflates the lungs near maximum respiratory capacity that may cause pulmonary parasympathetic stimulation, and consequently sympathetic activity reduction and an increase in blood flow to the limbs, resulting in a flush of metabolites and attenuation of vasoconstriction. ${ }^{43}$ Therefore, in patients with essential hypertension, blood pressure reduction has been associated with sympathetic activation reduction and parasympathetic increase. ${ }^{9}$ Moreover, IMT has been associated with reduction in respiratory muscle oxygen demand/delivery mismatch and consequently reduces respiratory fatigue in heart failure patients. ${ }^{40}$

Low versus moderate-high intensity IMT protocols appear to elicit differences in HR and DBP with low-intensity IMT protocols associated with a reduction in HR reduction, which might be related to the greater number of repeated respiratory maneuvers, not possible with moderate-high intensity IMT, that facilitated a reduction in sympathetic nervous system activity. Conversely, moderate-high intensity protocols are more likely to stimulate mechanoreceptors insofar as vascular occlusion as a result of muscle contraction which has been related to an increase in $\mathrm{BP}^{45}$

\section{Clinical implications}

The studies included in this meta-analysis found that IMT increases MIP and has a modest effect in only one of the HRV outcomes. IMT also decreased HR and DBP, but only in low or moderate-high intensity protocols alone. Cardiovascular patients were the main population in this review (6/10 studies).

\section{Limitations}

This present systematic review and meta-analysis have limitations that warrant consideration. The major limitation is related to the limited number of publications eligible for consideration and poor to modest study quality. Another limitation regards the moderate to high degree of heterogeneity in the studies analyzed, which is likely related to the different patient populations and variable characteristics investigated in this small number of RCTs.

\section{Conclusion}

IMT is an effective treatment for inspiratory muscle weakness in several populations and according to this review might also be considered as a complementary treatment for cardiovascular modulation mainly for HR and DBP. Further studies are required to understand better the role of IMT as a component or alternative to regular exercise protocols.

\section{Disclosure}

The authors declare that there are no conflicts of interest in this work.

\section{References}

1. McConnell AK, Lomax M. The influence of inspiratory muscle work history and specific inspiratory muscle training upon human limb muscle fatigue. J Physiol. 2006;577(Pt 1):445-457. doi:10.1113/ jphysiol.2006.117762

2. Romer LM, Lovering AT, Haverkamp HC, Pegelow DF, Dempsey JA. Effect of inspiratory muscle work on peripheral fatigue of locomotor muscles in healthy humans. $J$ Physiol. 2006;571(Pt 2):425-439. doi:10.1113/jphysiol.2005.099697

3. Dempsey JA, Sheel AW, St Croix CM, Morgan BJ. Respiratory influences on sympathetic vasomotor outflow in humans. Respir Physiol Neurobiol. 2002;130(1):3-20. doi:10.1016/S0034-5687(01)00327-9

4. Romer LM, Polkey MI. Exercise-induced respiratory muscle fatigue: implications for performance. J Appl Physiol (1985). 2008;104 (3):879-888.

5. Ribeiro JP, Chiappa GR, Callegaro CC. The contribution of inspiratory muscles function to exercise limitation in heart failure: pathophysiological mechanisms. Rev Bras Fisioter. 2012;16(4):261-267. doi:10.1590/S1413-35552012005000034

6. Neves LM, Karsten M, Neves VR, Beltrame T, Borghi-Silva A, Catai AM. Relationship between inspiratory muscle capacity and peak exercise tolerance in patients post-myocardial infarction. Heart Lung. 2012;41(2):137-145. doi:10.1016/j.hrtlng.2011.07.010

7. Filusch A, Ewert R, Altesellmeier M, et al. Respiratory muscle dysfunction in congestive heart failure-the role of pulmonary hypertension. Int $J$ Cardiol. 2011;150(2):182-185. doi:10.1016/j.ijcard.2010.04.006

8. Posser SR, Callegaro CC, Beltrami-Moreira M, Moreira LB. Effect of inspiratory muscle training with load compared with sham training on blood pressure in individuals with hypertension: study protocol of a double-blind randomized clinical trial. Trials. 2016;17:382. doi:10.1186/s13063-016-1514-y

9. Ferreira JB, Plentz RD, Stein C, Casali KR, Arena R, Lago PD. Inspiratory muscle training reduces blood pressure and sympathetic activity in hypertensive patients: a randomized controlled trial. Int $J$ Cardiol. 2013;166(1):61-67. doi:10.1016/j.ijcard.2011.09.069 
10. Hunt BE, Fahy L, Farquhar WB, Taylor JA. Quantification of mechanical and neural components of vagal baroreflex in humans. Hypertension. 2001;37(6):1362-1368. doi:10.1161/01.HYP.37.6.1362

11. Kaminski DM, Schaan BD, Da Silva AM, Soares PP, Lago PD. Inspiratory muscle training in patients with diabetic autonomic neuropathy: a randomized clinical trial. Clin Autonomic Res. 2015;25 (4):263-266. doi:10.1007/s10286-015-0319-5

12. Witt JD, Guenette JA, Rupert JL, McKenzie DC, Sheel AW. Inspiratory muscle training attenuates the human respiratory muscle metaboreflex. J Physiol. 2007;584(Pt 3):1019-1028. doi:10.1113/ jphysiol.2007.140855

13. Dall'Ago P, Chiappa GR, Guths H, Stein R, Ribeiro JP. Inspiratory muscle training in patients with heart failure and inspiratory muscle weakness: a randomized trial. J Am Coll Cardiol. 2006;47(4):757763. doi:10.1016/j.jacc.2005.09.052

14. HajGhanbari B, Yamabayashi C, Buna TR, et al. Effects of respiratory muscle training on performance in athletes: a systematic review with meta-analyses. J Strength Cond Res. 2013;27(6):1643-1663. doi:10.1519/JSC.0b013e318269f73f

15. de Abreu RM, Rehder-Santos P, Minatel V, Dos Santos GL, Catai AM. Effects of inspiratory muscle training on cardiovascular autonomic control: a systematic review. Auton Neurosci. 2017;208:29-35. doi:10.1016/j.autneu.2017.09.002

16. Liberati A, Altman DG, Tetzlaff J, et al. The PRISMA statement for reporting systematic reviews and meta-analyses of studies that evaluate healthcare interventions: explanation and elaboration. BMJ. 2009;339..

17. Maher CG, Sherrington C, Herbert RD, Moseley AM, Elkins M. Reliability of the PEDro scale for rating quality of randomized controlled trials. Phys Ther. 2003;83(8):713-721.

18. Nobre E Souza MA, Lima MJ, Martins GB, et al. Inspiratory muscle training improves antireflux barrier in GERD patients. Am J Physiol Gastrointest Liver Physiol. 2013;305(11):G862-867. doi:10.1152/ ajpgi.00093.2013

19. Jones CU, Sangthong B, Pachirat O, Jones DA. Slow breathing training reduces resting blood pressure and the pressure responses to exercise. Physiological Res. 2015;64(5):673-682.

20. Drozdz T, Bilo G, Debicka-Dabrowska D, et al. Blood pressure changes in patients with chronic heart failure undergoing slow breathing training. Blood Press. 2016;25(1):4-10.

21. Gething AD, Passfield L, Davies B. The effects of different inspiratory muscle training intensities on exercising heart rate and perceived exertion. Eur J Appl Physiol. 2004;92(1-2):50-55. doi:10.1007/ s00421-004-1044-2

22. Jaenisch RB, Bertagnolli M, Borghi-Silva A, Arena R, Lago PD. Respiratory muscle training improves diaphragm citrate synthase activity and hemodynamic function in rats with heart failure. Braz $J$ Cardiovasc Surg. 2017;32(2):104-110.

23. Laohachai K, Winlaw D, Selvadurai $\mathrm{H}$, et al. Inspiratory muscle training is associated with improved inspiratory muscle strength, resting cardiac output, and the ventilatory efficiency of exercise in patients with a fontan circulation. J Am Heart Assoc. 2017;6:8. doi:10.1161/JAHA.117.005750

24. Laoutaris ID, Dritsas A, Brown MD, et al. Effects of inspiratory muscle training on autonomic activity, endothelial vasodilator function, and N-terminal pro-brain natriuretic peptide levels in chronic heart failure. $J$ Cardiopulm Rehabil Prev. 2008;28(2):99-106. doi:10.1097/01.HCR.0000314203.09676.b9

25. Logtenberg SJ, Kleefstra N, Houweling ST, Groenier KH, Bilo HJ. Effect of device-guided breathing exercises on blood pressure in hypertensive patients with type 2 diabetes mellitus: a randomized controlled trial. J Hypertens. 2007;25(1):241-246. doi:10.1097/ HJH.0b013e32801040d5

26. Mourya M, Mahajan AS, Singh NP, Jain AK. Effect of slow- and fast-breathing exercises on autonomic functions in patients with essential hypertension. $J$ Altern Complementary Med. 2009;15 (7):711-717. doi:10.1089/acm.2008.0609
27. Tong TK, McConnell AK, Lin H, Nie J, Zhang H, Wang J. "Functional" inspiratory and core muscle training enhances running performance and economy. J Strength Cond Res. 2016;30(10):29422951. doi:10.1519/JSC.0000000000000656

28. Passfield L, Dobbins T, Myers S, Reilly M, Williams EM. Acute cardio-respiratory changes induced by hyperpnoea using a respiratory muscle trainer. Ergonomics. 2005;48(11-14):1423-1432. doi:10.1080/00140130500101510

29. Correa AP, Antunes CF, Figueira FR, de Castro MA, Ribeiro JP, Schaan BD. Effect of acute inspiratory muscle exercise on blood flow of resting and exercising limbs and glucose levels in type 2 diabetes. PLoS One. 2015;10(3):e0121384. doi:10.1371/journal.pone.0121384

30. Jaenisch RB, Hentschke VS, Quagliotto E, et al. Respiratory muscle training improves hemodynamics, autonomic function, baroreceptor sensitivity, and respiratory mechanics in rats with heart failure. $J$ Appl Physiol. 2011;111(6):1664-1670. doi:10.1152/japplphysiol. 01245.2010

31. Sangthong B, Ubolsakka-Jones C, Pachirat O, Jones DA. Breathing training for older patients with controlled isolated systolic hypertension. Med Sci Sports Exerc. 2016;48(9):1641-1647. doi:10.1249/ MSS.0000000000000967

32. Vivodtzev I, Tamisier R, Croteau M, et al. Ventilatory support or respiratory muscle training as adjuncts to exercise in obese CPAPtreated patients with obstructive sleep apnoea: a randomised controlled trial. Thorax. 2018;73(7):634. doi:10.1007/s00421-017-3750-6

33. Legg Ditterline BE, Aslan SC, Randall DC, Harkema SJ, Castillo C, Ovechkin AV. Effects of respiratory training on heart rate variability and baroreflex sensitivity in individuals with chronic spinal cord injury. Arch Phys Med Rehabil. 2018;99(3):423-432. doi:10.1016/j. apmr.2017.06.033

34. Dos Santos Silva M, Mostarda C, Lopes GS. Inspiratory muscle training reduces sympathetic modulation in elderly patients with insulin resistance. J Diabetes Sci Technol. 2013;7(6):1654-1656. doi: $10.1177 / 193229681300700630$

35. Campos NG, Marizeiro DF, Florencio ACL, et al. Effects of respiratory muscle training on endothelium and oxidative stress biomarkers in hemodialysis patients: a randomized clinical trial. Respir Med. 2018;134:103-109. doi:10.1016/j.rmed.2017.12.005

36. Correa AP, Ribeiro JP, Balzan FM, Mundstock L, Ferlin EL, Moraes RS. Inspiratory muscle training in type 2 diabetes with inspiratory muscle weakness. Med Sci Sports Exerc. 2011;43(7):1135-1141. doi:10.1249/MSS.0b013e3181edefaa

37. DeLucia CM, De Asis RM, Bailey EF. Daily inspiratory muscle training lowers blood pressure and vascular resistance in healthy men and women. Exp Physiol. 2018;103(2):201-211. doi:10.1113/ eph.2018.103.issue-2

38. Mello PR, Guerra GM, Borile S, et al. Inspiratory muscle training reduces sympathetic nervous activity and improves inspiratory muscle weakness and quality of life in patients with chronic heart failure: a clinical trial. J Cardiopulm Rehabil Prev. 2012;32(5):255-261. doi:10.1097/HCR.0b013e31825828da

39. Mills DE, Johnson MA, Barnett YA, Smith WH, Sharpe GR. The effects of inspiratory muscle training in older adults. Med Sci Sports Exerc. 2015;47(4):691-697. doi:10.1249/MSS.0000000000000651

40. Moreno AM, Toledo-Arruda AC, Lima JS, Duarte CS, Villacorta H, Nobrega ACL. Inspiratory muscle training improves intercostal and forearm muscle oxygenation in patients with chronic heart failure: evidence of the origin of the respiratory metaboreflex. $J$ Card Fail. 2017;23(9):672-679. doi:10.1016/j.cardfail.2017.05.010

41. Rodrigues GD, Gurgel JL, Goncalves TR, da Silva Soares PP. Inspiratory muscle training improves physical performance and cardiac autonomic modulation in older women. Eur J Appl Physiol. 2018;118(6):1143-1152. doi:10.1007/s00421-017-3750-6

42. Vranish JR, Bailey EF. Inspiratory muscle training improves sleep and mitigates cardiovascular dysfunction in obstructive sleep apnea. Sleep. 2016;39(6):1179-1185. doi:10.5665/sleep.5826 
43. Feriani DJ, Coelho HJJ, Scapini KB, et al. Effects of inspiratory muscle exercise in the pulmonary function, autonomic modulation, and hemodynamic variables in older women with metabolic syndrome. $J$ Exerc Rehabil. 2017;13(2):218-226. doi:10.12965/jer.1734896.448

44. Romer LM, McConnell AK. Specificity and reversibility of inspiratory muscle training. Med Sci Sports Exerc. 2003;35(2):237-244. doi:10.1249/01.MSS.0000048642.58419.1E
45. Weippert M, Behrens M, Gonschorek R, Bruhn S, Behrens K. Muscular contraction mode differently affects autonomic control during heart rate matched exercise. Front Physiol. 2015;6:156. doi:10.3389/fphys.2015.00098

\section{Publish your work in this journal}

Integrated Blood Pressure Control is an international, peer-reviewed open-access journal focusing on the integrated approach to managing hypertension and risk reduction. Treating the patient and comorbidities together with diet and lifestyle modification and optimizing healthcare resources through a multidisciplinary team approach constitute key features of the journal. This journal is indexed on
American Chemical Society's Chemical Abstracts Service (CAS). The manuscript management system is completely online and includes a very quick and fair peer-review system, which is all easy to use. Visit http://www.dovepress.com/testimonials.php to read real quotes from published authors. 